\title{
NOTAS
}

\section{LOS EDITORES DE LAURA MÉNDEZ DE CUENCA}

El propósito de este artículo será realizar una breve reseña sobre las ediciones póstumas de los poemas de Laura Méndez de Cuenca, poniendo especial énfasis en la reciente edición de su Poesía. La escritora nació en la Hacienda de Tamariz, parroquia de Santiago Ayapango, Amecameca, jurisdicción de Chalco, Estado de México, el 18 de agosto de 1853 y murió en San Pedro de los Pinos, Distrito Federal, el 1 de noviembre de 1928, luego de haber vivido con intensidad pasiones e indecible dolor, tras padecer orfandades y viudez, pobreza, incomprensión, burocracia e incertidumbre, y luego de luchar durante sus últimos años contra una "diabetes glucosúrica crónica", que unos meses antes de su fallecimiento la había dejado ciega y sin ánimos para seguir viviendo ${ }^{1}$.

Antes de la edición de su Poesía, que realizó Pablo Mora con la colaboración de Roberto Sánchez Sánchez ${ }^{2}$, incluida en el tomo segundo de la obra monumental que coordinó Mílada Bazant y publi-

1 Mílada Bazant, Laura Méndez de Cuenca: mujer indómita y moderna (1853-1928). Vida cotidiana y entorno, Gobierno del Estado de México-El Colegio Mexiquense, Toluca, 2009, pp. 437-438.

2 En el "Estudio introductorio" de Impresiones de una mujer a solas, Mora señaló: "Este trabajo de rescate se debe fundamentalmente a Roberto Sánchez Sánchez quien realiza un trabajo más extenso sobre las crónicas de Laura Méndez de Cuenca”. Y en el "Estudio introductorio" de Poesía, Mora volvió a señalar: "La recopilación de la obra completa de la poesía de Laura $[$ sic] se debe mayormente a los trabajos meticulosos y puntuales de Roberto Sánchez Sánchez, investigador que también ha rescatado la obra cuentística y cronística de la escritora mexiquense", véase LAURA MÉndez de Cuenca, Impresiones de una mujer a solas. Una antología general, sel. y est. Pablo Mora, ensayos críticos de A. R. Domenella, L. Gutiérrez de Velasco y R. Sánchez Sánchez, F.C.E.-Fondo para las Letras Mexicanas-UNAM, México, 2006, p. 16 n.; y L. Méndez de Cuenca, Poesía, en Mílada Bazant (coord.), Laura Méndez de Cuenca. Su herencia cultural. T. 2, comp. R. Sánchez Sánchez, est. introd. P. Mora, Siglo XXI-Servicios Educativos Integrados del Estado de México-El Colegio Mexiquense, México, 2011, p. 27. 
có el Gobierno del Estado de México en 2011: Laura Méndez de Cuenca. Su herencia cultural, la obra poética de Laura Méndez de Cuenca sólo podía leerse, si acaso, en antologías.

Fueron sus primeros editores modernos Guillermo Servín Ménez y Rodolfo García Gutiérrez, quienes al publicar Mariposas furtivas -en 1953- "como homenaje a la eximia poetisa y escritora... en ocasión del primer centenario de su nacimiento", advirtieron que no se trataba "propiamente hablando de una antología", sino nada más de un "opúsculo", impreso gracias al patrocinio del Grupo "Letras", al que los editores pertenecían; esta breve muestra incluyó diez poemas: "Nieblas”, “¡Oh, corazón!”, "Mesalina”, "Magdalena”, "Invierno”, “Adiós”, "Fe", "Al pasar el regimiento", "In memoriam. Ante la tumba de José María Bustillos", "Los capones de Navidad" y fragmentos de "El esclavo. (Canto único)"; se dio a la estampa con una "Introducción" firmada por sus editores y con una "Nota biográfica" colocada como apéndice, la cual fue tomada de una obra de Gonzalo Pérez Gómez, entonces en preparación, la Antología poética del Estado de México ${ }^{3}$.

El segundo editor fue precisamente Gonzalo Pérez Gómez, quien compiló e introdujo la antología Poesía rediviva en 1977. El prólogo tuvo como antecedente aquella "Nota biográfica" copiada en Mariposas furtivas, a pesar de que se trataba, en realidad, de una versión ampliada. Poesía rediviva presentó estos poemas no reunidos en libro: "Bañada en lágrimas", "Caridad", "Tristezas", "Lágrimas", "Sombras", "Kyrie eleison", "Cuarto menguante", "Tempestad", "Los cavadores", "La abuelita sueña”, “Tentación”, "Salve”, "En el álbum de la señorita María Stern" [ sic: Stein], "Sequía" y "Pasa un poeta", y se incluyeron por primera vez en volumen las traducciones de los poemas "Annabel Lee", "A Sextio", "Rectius vives"y "Coloquio con los árboles"4.

Puede decirse que Poesía rediviva reagrupaba los materiales que Pérez Gómez había localizado en los periódicos de época, y aunque adoleció de algunas inconsistencias, reorganizó los materiales poéticos que había compartido con Servín Ménez y García Gutiérrez, y que luego volvería a utilizar para reunir la "Antología” que dio a conocer en 1968 en el Boletín Bibliográfico número 6 de la Biblioteca Pública de Toluca. Pérez Gómez añadió al volumen la fotografía de la poetisa y la viñeta a lápiz que le hizo Edmundo Calderón ${ }^{5}$.

3 Laura Méndez de Cuenca, Mariposas furtivas. (Versos), introd. y comp. Guillermo Servín Ménez y Rodolfo García Gutiérrez, Eds. Integrales, Toluca, 1953, pp. 4 y $43-44$.

4 L. Méndez de Cuenca, Poesía rediviva, comp. y ficha biográfica de G. Pérez Gómez, Gobierno del Estado de México, Toluca, 1977, pp. 13-98.

5 L. Méndez de Cuenca, La pasión a solas. Antología, pres. Francisco Valero Becerra, sel., pról. y notas de Raúl Cáceres Carenzo, Gobierno del Estado de MéxicoInstituto Mexiquense de Cultura, Toluca, 2003, p. 168. 
El poeta Raúl Cáceres Carenzo, más que un editor o un académico, ha sido un lector acucioso y persistente de la poesía y las obras de Laura Méndez de Cuenca. Por eso, a partir del prólogo que escribió para la primera edición de su antología La pasión a solas ${ }^{6}$, solamente ha ido agregando, en las ediciones subsiguientes, las novedades y pesquisas llevadas a cabo por los críticos, lectores e investigadores, a las que ha añadido sus comentarios, con lo cual ha ido perfeccionando sus "notas de lectura"7.

Muestra de ese interés por ir agregando los hallazgos bibliográficos ha sido la incorporación, en la tercera edición de La pasión a solas, del apartado "Dos cuentos y un ensayo", el poema elegíaco "Siemprevivas" y el enriquecimiento de la sección de "Iconografía"; como el prologuista lo acredita en su sitio, una copia de ese poema le fue proporcionada por Francisco Valero ${ }^{8}$. Méndez de Cuenca había escrito este poema a petición de Cayetano Rodríguez Beltrán, quien por encomienda de la Academia Mexicana de la Lengua organizó el homenaje nacional a la memoria de la poetisa Josefa Murillo ${ }^{9}$. El poema abría el "Libro segundo" del Homenaje, en el que, entre otros, colaboraron Rafael Delgado, Jesús E. Valenzuela, Porfirio Parra, Juan de Dios Peza, Amado Nervo, Miguel Bolaños Cacho, Juan B. Delgado, Francisco Sosa, Manuel E. Rincón, Manuel Larrañaga Portugal, José Peón del Valle y Luis G. Urbina ${ }^{10}$.

Cáceres Carenzo ha tenido el cuidado de contextualizar los tiempos de la creación de los poemas y organizarlos en forma temática -a esto lo ha denominado "orden «poético»"-; así, ha clasificado los poemas en apartados de lírica amorosa, paisaje anímico, intenciones ética y religiosa, el mundo de la infancia, los testimonios sociales, los poemas elegíacos y sus traducciones. Asimismo, ha tenido el cuidado de señalar siempre que para la hechura de La pasión a solas su selección ha partido "esencialmente, de la recopilación de Poesía rediviva que realizó Gonzalo Pérez Gómez”11. Esto quiere decir, finalmente,

${ }^{6}$ L. Méndez de Cuenca, La pasión a solas, sel. y pról. R. Cáceres Carenzo, Gobierno del Estado de México, Toluca, 1984, 101 pp. y La pasión a solas. (Antología poética), $2^{a}$ ed., sel., pról. y notas de R. Cáceres Carenzo, Instituto Mexiquense de Cultura, Toluca, 1989, 91 pp.

7 Méndez de Cuenca, La pasión a solas. Antología, p. 19.

8 Ibid., pp. 9, 24, 28 y 113-114.

9 Josefa Murillo nació en Tlacotalpan, Veracruz, el 28 de febrero de 1860 -no en 1850, como ha señalado Mora-y murió en su pueblo natal, el 1 de septiembre de 1898. Véase Méndez de Cuenca, Impresiones de una mujer a solas, p. 20; Poesía, p. 5 y Esther Hernández Palacios y Ángel José Fernández, Veracruz: dos siglos de poesía (XIX y XX), Conaculta, México, 1991, t. 2, pp. 635-636.

10 Homenaje a la inspirada poetisa tlacotalpeña Josefa Murillo / + 1 de septiembre de 1898, Segundo libro, capítulo II. Composiciones inéditas, Tipografía, Encuadernación y Rayados La Reforma, Tlacotalpan, 1899, pp. 83-84 y 79-137.

11 Méndez de Cuenca, La pasión a solas. Antología, p. 24. 
que Cáceres Carenzo no hizo ni ha hecho investigación; pero en cambio se ha consagrado a acercar la poesía de Méndez de Cuenca a los lectores. Últimamente, preparó el prólogo para el apartado Miscelánea, incluido también en el segundo tomo de Laura Méndez de Cuenca. Su herencia cultural ${ }^{12}$.

Se completa el elenco de editores modernos con Pablo Mora, quien pocos años antes de dar a conocer la edición de la Poesía de Méndez de Cuenca escogió veinte poemas que incorporó a la antología Impresiones de una mujer a solas, en donde dio como primicias estos poemas hasta entonces no reunidos en libro: "Cineraria”, "¡Ayer! (Fragmento de un poema)", "Rayo de sol", la versión íntegra de "El esclavo. (Canto único)", "De viaje" y "Ya sabes el enigma"13, y preparó el "Estudio introductorio" que tituló "Laura Méndez de Cuenca: escritura y destino entre siglos (XIX-XX)"14. Además, seleccionó quince cuentos, un grupo de ocho cartas (entresacadas de las enviadas por la poetisa a su maestro Enrique de Olavarría y Ferrari), catorce crónicas, una semblanza de Benito Juárez y el informe "Kindergarten". Como corolario del amplio "Estudio introductorio", que abarca todas las vertientes de su creación literaria, periodística y pedagógica, pero en donde tomó como eje vertebral la obra poética, Mora añadió al volumen un par de "Ensayos críticos" complementarios: uno sobre su narrativa, preparado por Ana Rosa Domenella y Luzelena Gutiérrez de Velasco, y otro más, en el que Roberto Sánchez Sánchez trabajó el tema de las crónicas ${ }^{15}$. Sánchez Sánchez revisó sobre todo las experiencias de Méndez de Cuenca en su etapa europea, que duró casi cuatro años completos, pues comenzó en el mes de agosto de 1906 y culminó -junto con el finiquito de sus misiones oficiales- en los primeros días de julio de $1910^{16}$.

Como se ha dicho, Mora tomó "como hilo conductor" de su "Estudio introductorio" la constancia poética que la escritora había mostrado "a lo largo de su vida"17. Esta idea, sensata, viable, incluso plausible, tuvo también el peligro que ha implicado la escasez de fondos hemerográficos para el auxilio de investigadores y editores, a pesar de que es bien sabido el papel que ejerció sobre la vida cultural, social y política de México la ingente actividad de la prensa durante la segunda mitad del siglo xIx y en el primer cuarto del xx, y sobre todo porque, al no haberse publicado en libro la mayor parte de las obras de

12 M. Bazant (coord.), Laura Méndez de Cuenca. Su herencia cultural, t. 2, pp. 431-449.

13 Méndez de Cuenca, Impresiones de una mujer a solas, pp. 71-111.

14 Ibid., pp. 15-68.

15 Ibid., pp. 331-350 y 351-367.

16 "Doña Laura Méndez de Cuenca", en La Iberia. Diario mexicano de la mañana, México, año V (sábado 16 de julio de 1910), núm. 1242, p. 4.

17 Méndez de Cuenca, Impresiones de una mujer a solas, pp. 21-22. 
nuestros escritores -como fue el caso de la poesía, los artículos y las crónicas de Méndez de Cuenca-, la prensa escrita habría de convertirse en fuente primordial para el acopio, la compilación y desde luego la compulsa y el cotejo de las obras. El hecho, al parecer real, de no contar con la totalidad de las publicaciones de los poemas en todas las fuentes periodísticas y en las antologías o anuarios en donde aparecieron, debilitaron, por desgracia, el planteamiento de tomar como eje del "Estudio introductorio" sólo algunos ejemplos de su producción poética.

Esto y la carencia que entonces había de una biografía confiable de la escritora, que Mílada Bazant ha venido a cubrir, si no con total plenitud por lo menos con fundamentada suficiencia, al dar a la estampa Laura Méndez de Cuenca: mujer indómita y moderna (1853-1928). Vida cotidiana y entorno, pudieran justificar en gran medida las deficiencias. En suma, la falta de información biográfica y textual ha impedido que los trabajos editoriales de Pablo Mora sean definitivos ${ }^{18}$.

Pese a lo dicho, la aparición de la Poesía implica un acto de justicia, una enmienda histórica, o si se prefiere una reposición, tanto del nombre como de la obra de Laura Méndez de Cuenca. Al ponerla a circular en una edición moderna e íntegra -los poemas pendientes de localizar, además de no ser muchos, en poco modificarán el juicio estético que se tiene de su obra-, la autora se incorpora al conjunto de la literatura mexicana. Hoy que se le restituye para las letras, conviene preguntarse la razón de esta verdadera anomalía, cometida por la propia escritora. ¿Por qué no consolidó los originales de su poesía, y en general de sus obras, cuando bien pudo hacerlo?

Sus obras literarias, a excepción de su tomo de cuentos, habían quedado dispersas, en particular su poesía, diseminada en los periódicos de la Ciudad de México y del interior de la República, en las prensas peruana, argentina y uruguaya, en los periódicos de Madrid y Barcelona e, inclusive, en algunos de la prensa norteamericana. Méndez de Cuenca no organizó sus materiales, seguramente, por carecer de medios para editarlos (recuérdese que en 1910 había hecho imprimir a sus costas, en París, su libro de cuentos Simplezas) ${ }^{19}$; no dejó,

18 Por lo que respecta a la investigación de Mílada BAzAnt, como ella misma ha dicho, adolece de "algunos vacíos” biográficos. Por eso determinó llenarlos con hechos inventados, de "ficción"; con ellos, cubrió los "huecos" que "le dejaba la historia". Complementaba esta idea en su "Introducción": "Esta pequeña dosis de ficción tiene el objetivo de lograr una historia más fluida, vívida y rica. Debo remarcar que aquellos pedazos de ficción han sido reconstruidos con base en pasajes verosímiles, fieles a la realidad del pasado" (Laura Méndez de Cuenca: mujer indómita y moderna [1853-1928], p. 17).

19 L. Méndez de Cuenca, Simplezas, Sociedad de Ediciones Literarias y Artísticas, Librería Paul Ollendorff, 50 Chausée D’Antin, 50 [impreso por Eugenio Aubin, Ligugé, Vienne], Paris, 1910. 
pues, ni obra poética reunida ni instrucciones para publicarla, y por estas razones ha provocado que sólo se le conozca en forma parcial, nada más por aquellos poemas que se han reproducido y siguen apareciendo en las antologías, o por la compilación de Mora, de cuyas deficiencias trataremos en adelante.

Agustín F. Cuenca, al contrario de su esposa, dejó listo el manuscrito de sus poemas, aunque éste nunca llegó a publicarse en libro. Al morir el 30 de junio de 1884, a la edad de 33 años y a consecuencia de una "hepatitis supurada", nadie tuvo la impresión de que sus versos iban a permanecer inéditos durante más de un siglo ${ }^{20}$. Su funeral, por cruel paradoja, fue presagio del silencio en que caería su expresión poética, ya que con su muerte pareció sepultarse de igual modo su palabra escrita. El Nacional publicó la reseña del sepelio: "Nadie quiso decir una palabra al descender al sepulcro el ataúd de Cuenca" "21. Sus amigos Aurelio Horta y Manuel Gutiérrez Nájera escribieron sobre su vida y su obra en La Libertad ${ }^{22}$, y desde este periódico convocaron a la opinión pública para que se produjera "a prorrata una edición de sus versos, constituyéndose la propiedad en favor de la viuda y los hijos del autor" ${ }^{23}$. Nada pasó ${ }^{24}$.

Cuenca también puso en manos de su viuda el manuscrito definitivo de su drama La cadena de hierro, luego de haberlo presentado ante la Sociedad de Escritores Dramáticos Manuel Eduardo de Gorostiza para que lo calificara la censura -lo que se efectuó en enero de $1876^{25}$-; también logró que se pusiera en escena en el Teatro Principal de México, el 20 de agosto siguiente. La Sociedad Gorostiza acordó, el día 23 de ese mismo mes y año:

20 “Gacetilla”, en La Prensa, México, segunda época (martes 1 de julio de 1884), núm. 96, p. 3.

21 “Inhumación”, en El Nacional, México, año VI, t. 6 (viernes 4 de julio de 1884), núm. 128, p. 3.

22 Aurelio Horta, “Agustín F. Cuenca”, en La Libertad, México, año VII (jueves 3 de julio de 1884), núm. 147, p. 1; y Manuel Gutiérrez Nájera, "Agustín F. Cuenca”, en ibid., p. 2.

23 “La Libertad”, en El Nacional, México, año VI, t. 6 (viernes 4 de julio de 1884), núm. 128, p. 3.

24 Cuando estaba en preparación este artículo, comenzó a circular en volumen la poesía de Agustín F. Cuenca, que incluye sus poemas y una breve antología de sus artículos literarios y discursos políticos. Lo presenté junto con el compilador en el marco de la XXXV Feria Internacional del Libro del Palacio de Minería el 21 de febrero del presente año. Esta edición es importante, pues representa el primer acercamiento al público de un conjunto de obras del esposo de Laura Méndez de Cuenca. Véase Agustín F. Cuenca, Obra literaria, comp., ed. y est. introd. E. Ortiz Domínguez, Editora de Gobierno del Estado de Veracruz, Xalapa, 2014.

25 Alicia Perales OJEDA, Asociaciones literarias mexicanas. Siglo XIX, Imprenta Universitaria, México, 1957, p. 147. 
...hacer una elegante impresión de la obra dramática referida, para obsequiar con ella a su laureado autor. La edición deberá contener el examen crítico del drama, los juicios de la prensa periodística acerca de ella, y una comunicación congratulatoria que, juntamente con una corona de laureles le debe presentar a Cuenca una comisión de la "Sociedad Gorostiza" 26 .

No hubo tal edición. Finalmente, este drama se publicó en Orizaba, en edición de autor, en la Imprenta Popular de Juan C. Aguilar el año $1881^{27}$. La cadena de hierro no ha sido reimpresa y el proyecto de publicar en libro sus versos pronto se desvaneció hasta olvidarse. ¿Qué fue lo que ocurrió a final de cuentas?

Lo cierto es que cuando Laura Méndez de Cuenca experimentaba el duelo por su viudez, en la prensa de México se ventiló y reveló, en noviembre de 1884, un caso de adulterio cometido por su esposo, que se hizo evidente cuando, al aparecer impresas unas décimas firmadas por Agustín F. Cuenca -en la antología Jardín mexicano. Semblanzas femeninas-, con la dedicatoria “a la señorita Tornel”, la viuda pidió en forma inmediata una "Rectificación"28. Miguel Ulloa, compilador de aquella antología, respondió: "Cúmpleme decir, por mi parte, que recibí esa poesía por conducto de mi amigo Joaquín Trejo, que me ayudaba en la recolección de materiales para el libro, que era íntimo del poeta que hoy lloramos todos, y que, según me ha dicho, conserva el original como un precioso recuerdo del autor"29.

Sin sospecharlo la viuda, Cuenca resultó ser "el verdadero cantor de la señorita Tornel”. El golpe que recayó en la esposa trajo de igual modo como consecuencia el "abandono" de sus escritos; Méndez de Cuenca abandonó los de su difunto marido, como después habría de abandonar los propios, pues el episodio se tornó en pésimo antecedente. Corrobora lo anterior la nota que Manuel Toussaint puso al final de su prólogo a Poemas selectos de Agustín F. Cuenca:

Agradecemos profundamente, a la esposa del artista, la señora doña Laura Méndez de Cuenca, la autorización para publicar este volumen. Sobre originales proporcionados por dicha señora, ha sido hecha la

26 "La sociedad «Gorostiza»", en El Socialista, México, año séptimo (domingo 27 de agosto de 1876), núm. 191, p. 3. El legajo con el manuscrito de La cadena de hierro y el examen crítico de I. M. Altamirano, al que aquí se ha hecho referencia, lo conserva en la actualidad Carlos Beteta de la Garza, descendiente de la familia Méndez Lefort.

27 Joaquín Díaz Mercado, Bibliografía general del Estado de Veracruz. T. 1, 17941910, D. A. P. P., México, 1937, p. 67.

28 "Remitido", en El Nacional, México, año VI, t. 6 (jueves 13 de noviembre de 1884), núm. 237, pp. 1-2.

29 "La señora viuda de Agustín F. Cuenca", en El Siglo XIX, México, novena época, año XLIV, t. 86 (viernes 14 de noviembre de 1884), núm. 13 976, p. 3. 
selección de poemas. Nos permitimos observar, empero, que dichos originales no son perfectos, ni contienen, siquiera, la totalidad de los versos de Cuenca ${ }^{30}$.

Cuando Pablo Mora compiló, editó y prologó la obra poética, escribió un nuevo "Estudio introductorio", ahora enfocando sobre todo los aspectos del decurso de su creación poética: "Laura Méndez de Cuenca: pasión y destino en la poesía mexicana" "31. A pesar de su especificidad, remite en muchos de sus contenidos y pasajes a lo ya expuesto en el que había preparado para Impresiones de una mujer a solas; pero, a diferencia del eje que había tomado entonces, siguió ahora la guía histórica de su lectura. Mora le dio particular importancia a su evolución y desarrollo como poetisa; la parte más importante de su estudio consistió en dar puntual reseña del trabajo poético, al que comparó con el de Salvador Díaz Mirón, su contemporáneo en riguroso sentido temporal (ambos artistas habían nacido en 1853 y los dos murieron en 1928). Inclusive, Mora estableció un paralelo entre las tres etapas creativas de Méndez de Cuenca y las tres épocas en que la crítica -y no Manuel Sol, el editor de Díaz Mirón, como erróneamente señaló- ${ }^{32}$ ha dividido la poesía del veracruzano, aunque éstas hayan sido definidas por compromisos y criterios exclusivamente estéticos: la primera época se cubriría con los poemas escritos en el período que va de 1874 a 1891; la segunda, con los que incluyó en Lascas, compuestos a partir de 1892; y la tercera sería la formada por los poemas arreglados con posterioridad a 1901, fecha de la impresión de Lascas, es decir, por lo que al final habrían de ser sus últimos poemas ${ }^{33}$.

Lo que no precisó Mora es que Laura Méndez de Cuenca tuvo, como artífice de la palabra poética, tres etapas o impulsos creadores en el proceso de su construcción, pero éstos no habían obedecido a un criterio estético ni se debieron a una búsqueda en el aspecto creativo o técnico como, en efecto, había sido en el caso de Díaz Mirón. Sus silencios y temporadas de esterilidad poética fueron más bien resultado de las circunstancias, como cuando se dedicó a la procreación y crianza de los siete hijos que concibió con Cuenca, o debido a causa de una necesidad práctica, al haber enviudado, como la de preparar artículos y escribir cuentos, o como mucho después, en que ocupó su tiempo en arreglar reseñas, informes técnicos y en escribir cuentos, crónicas y artículos de su experiencia europea.

30 Agustín F. Cuenca, Poemas selectos, pról. M. Toussaint, Eds. México Moderno, México, 1919 [fecha del colofón: 1920], p. xxi.

31 Méndez de Cuenca, Poesía, pp. 3-28.

32 Ibid., p. $10 \mathrm{n}$.

33 Salvador Díaz Mirón, Poesía completa, ed. Manuel Sol, F.C.E., México, 1997, pp. 91-146. 
En el nuevo "Estudio introductorio", Mora insiste acerca de varias conjeturas ya referidas. Por ejemplo, afirmó en 2006, y reafirmó en 2011, que Laura Méndez había tomado parte en el programa cultural de la Restauración de la República, que tuvo como guía al maestro Altamirano $^{34}$, y volvió a recalcar en 2011, aún sin sustento, que siendo apenas una adolescente, la futura escritora había colaborado, o al menos participado, en los trabajos y "sesiones de la Sociedad Netzahualcóyotl (1869)"35, es decir, cuando sólo contaba con dieciséis años de edad y en un universo tan marcadamente masculino como masónico.

En todo caso, es probable que haya estado presente, entre el público, en la ceremonia de reinstalación de esta misma Sociedad, efectuada el 9 de mayo de $1872^{36}$, el mismo día del estreno del drama El pasado de Manuel Acuña. Puede comprobarlo el hecho de que el 24 de abril anterior, el saltillense le había escrito el poema "A Laura. Epístola" -el primero de los de la saga que le compuso-, al cual habría de darle lectura el día 29 siguiente en el Conservatorio Nacional de Música, como parte de la ceremonia de otra reposición institucional: la del Liceo Hidalgo, cuyos trabajos también presidiría Altamirano. El poema fue publicado unos días después en las páginas del suplemento literario del periódico El Eco de Ambos Mundos ${ }^{37}$, y poco más tarde, en la sesión del Liceo celebrada el 6 de mayo, se aprobó que Acuña fuera socio titular junto a otros intelectuales, como José María Iglesias, José María Lafragua, Luis Calderón, Guillermo Prieto, Javier Santa María, Jesús Echaiz, Gerardo M. Silva, José María Malda, Eduardo Gibbon, Manuel Flores, Joaquín Gómez Vergara, Manuel Romo, Nicolás Pizarro Suárez, Manuel Lizaola, Francisco Pimentel y Antonio García Cubas ${ }^{38}$.

El mayor peso de las inconsistencias se resiente en el tomo de la Poesía, ya que se repitieron muchas de las que habían aparecido en 2006. El contenido de ese tomo se distribuyó en tres partes: una dedicada a la poesía original, otra a sus traducciones y una más, en donde se incluyó una selección de los “poemas dedicados a la poeta" Resulta pertinente aclarar que esta edición de la Poesía tuvo la fallida pretensión de haber sido establecida como edición crítica, pero no en todos los casos fueron presentados los poemas con sus aparatos de notas y variantes. Esta irregularidad, quizá, pueda entenderse si ponemos atención en lo que Mora explicó al respecto en la "Nota final de la edición":

34 Méndez de Cuenca, Impresiones de una mujer a solas, p. 23.

35 Méndez de Cuenca, Poesía, p. 6.

36 A. Perales OJeda, op. cit., pp. 82-83.

37 Manuel Acuña, "A Laura. Epístola”, en ElEco de Ambos Mundos, Imprenta de Ignacio Cumplido, Calle de los Rebeldes núm. 2, México, [1872], pp. 83-84.

38 “Liceo Hidalgo", en El Siglo XIX, México, séptima época, año XXXI, t. 54 (martes 7 de mayo de 1872), núm. 9 982, p. 3.

39 Méndez de Cuenca, Poesía, p. 26. 
hay que señalar que no fueron muchos los poemas repetidos que Laura Méndez de Cuenca publicó en distintas versiones en publicaciones diversas $[\mathrm{sic}]$. Por lo pronto, podemos advertir que durante la estancia de Laura en Estados Unidos, a partir de 1890 [sic: 1891], fue cuando envió más versiones de sus poemas con modificaciones significativas a distintas revistas mexicanas. Es por ello que hemos optado por hacer una selección de esos poemas e incluir la primera versión completa con las correcciones o modificaciones en notas a pie de página ${ }^{40}$.

Esta aclaración, por encima de su ambigüedad, resulta asimismo inexacta, pues Mora, además de desechar la idea de hacer una edición crítica, tampoco presentó al lector en todos los casos las versiones definitivas de muchos de sus poemas, hayan sido corregidos o no, reescritos o no, enmendados o no, durante su "estancia... en Estados Unidos", en México o en cualquier otro sitio. Hubiera sido un criterio razonable hacer acopio de las fuentes, enfrentarlas y cotejarlas, y realizar asimismo un aparato de variantes; sólo así podría consolidarse el manuscrito de una edición crítica.

A despecho de lo anterior, la edición de Poesía incurre en 1) yerros de imprenta (erratas y cambios de palabras); 2) falta de uno o varios versos, o mutilaciones de texto; 3) inconsistencias en las referencias de las fuentes a pie de página; 4) errores de carácter histórico y biográfico; 5) ausencia de un registro de fuentes que dé razón de las versiones de los poemas publicados en vida de la poetisa y, como consecuencia de lo anterior, 6) desconocimiento de algunas versiones definitivas de los poemas o anulación de la voluntad última de la poeta. Por razones de espacio se ha prescindido de la mayor parte de las enmiendas y sólo se tratará acerca de las que alteran la idea original de la autora. Veamos algunos de estos detalles.

La adición de algunas prosas. El editor incluyó en Poesía las prosas "Mercedes”, “Año nuevo”, “PPatria!” y "Cuando estemos muertos”41, que sin ser poemas en prosa o prosas poéticas cabrían en un tomo de poemas, a lo mejor dentro de un apéndice, pero no en el cuerpo de la poesía original. La primera es un obituario; la segunda, una salutación con motivo del año nuevo, y en las dos últimas predomina el carácter editorial. Y si el criterio hubiera sido reunir prosas con poemas, ¿por qué no se incluyó en el tomo la prosa "Mártires", que tiene contenido similar a las otras incluidas, publicada primero en La Juventud Literariay después en El Mundo, y por qué no el obituario "Don José Vicente Villada", que primero apareció en Diario del Hogar y después fue reunido en su Corona fúnebre? ${ }^{42}$

40 Ibid., p. 26.

41 Ibid., pp. 49-52, 115, 149-150 y 150-151.

42 "Mártires", en La Juventud Literaria, México, t. 1 (domingo 4 de septiembre de 1887), núm. 26, pp. 206-207; “¡Mártires!”, en El Mundo, México, t. 1 (8 de septiem- 
La atribución de un poema. El tomo de Poesía se inicia con un poema atribuido a Laura Méndez de Cuenca, tanto por el editor como por el compilador de la obra. Se trata del titulado "Un grito al corazón", resuelto en seis cuartetas de endecasílabos con rima consonante en serventesios (esquema $\mathrm{ABAB}$ ), dado a la estampa en La Sombra de Guerrero con el seudónimo $\mathrm{Sara}^{43}$; editor y compilador se lo atribuyeron a la poetisa, no obstante la aclaración que en ese impreso fue colocada en la "Gacetilla", en donde se afirmó que dicho seudónimo encubría la identidad de "una poetisa poblana". Mora justificó dicha inclusión "por el tono y la intensidad rítmica del poema”44, y Sánchez Sánchez, por su parte, en el "Estudio preliminar" de Simplezas y otros cuentos..., acotó: "En conversación personal con Pablo Mora coincidimos en la apreciación de que Sara es posiblemente un seudónimo de Laura Méndez; ya que los versos de «Un grito al corazón»-de métrica y figuras retóricas similares a las empleadas en los firmados con su nombre... nos anuncian la sensibilidad y la energía vital de la escritora mexicana" ${ }^{45}$.

Méndez de Cuenca publicó sus primeros poemas con el seudónimo $L$ *** (o la variante L...): "Era el mundo a mi vista... ", "Cineraria", "Adiós", "Esperanza”, “A Clemente Cantarell” e "Infortunio". El primer poema que firmó como Laura Méndez fue "Bañada en lágrimas", que apareció en El Siglo XIX ${ }^{46}$; no volvió a usar otro seudónimo, hasta donde se sabe, para publicar su poesía.

Ahora bien, utilizó cuartetos con rimas consonantes alternas en tres poemas elegíacos: en el titulado "Esperanza", que escribió y dedicó a la muerte de Acuña, dado a conocer en El Siglo XIX ${ }^{47}$; y los titulados “Hiere!” y "Lágrimas”, compuestos en el segundo semestre de 1884 a raíz de la muerte de su esposo ${ }^{48}$. Méndez de Cuenca usó este tipo de cuartetas cuando menos un par de años después de la fecha de publicación de "Un grito al corazón", o con mucho más tiempo de diferencia.

bre de 1889), núm. 57, p. 2; "Don José Vicente Villada”, en Diario del Hogar, México, año XXIII (martes 24 de mayo de 1904), núm. 215, p. 2; y Corona fúnebre del señor general don José Vicente Villada, gobernador del Estado de México, Oficina Tipográfica del Gobierno en la Escuela de Artes y Oficios, Toluca, 1905, pp. 50-51.

43 Sara: "Un grito al corazón", en La Sombra de Guerrero, México (1 de diciembre de 1872), núm. 2, s/p.; reproducido en Poesía, pp. 31-32.

44 Méndez de Cuenca, Poesía, p. 6 n.

45 L. Méndez de Cuenca, Simplezas y otros cuentos, ed., est. prel., notas e índices de R. Sánchez Sánchez, UNAM, México, 2010, p. 23.

46 L. Méndez, "Bañada en lágrimas", en El Siglo XIX, México, octava época, año XXXIV, t. 67 (martes 9 de febrero de 1875), núm. 10 947, p. 2.

47 L***, "Esperanza”, en El Siglo XIX, México, octava época, año XXXIII, t. 56 (domingo 26 de abril de 1874), núm. 10 698, p. 3.

48 “¡Hiere!”, en La Patria Ilustrada, México, año II (8 de diciembre de 1884), núm. 49, p. 781; y "Lágrimas”, en Revista Azul, Tipografía de El Partido Liberal, $3^{\text {a }}$ de la Independencia núm. 11, México, t. 3 (26 de mayo de 1895), núm. 4, p. 52. 
Por lo que respecta al contenido del texto, surgen más dudas que certezas: en los vv. 9-10 le dice al corazón: "Aún consagras al amor sagrado / puro y ferviente que logró inspirarte”. La verdad es que esto que se dice no concuerda con la mentalidad realista que desde su juventud mostró la autora; y los vv. 23-24, con los que se remata, resultan mucho menos indicativos de las formas que solía utilizar, pues allí también se altera su estilo, al espetarle de nueva cuenta al corazón: "Si finaliza tu existir amante / murmura un ¡te amo! y morirás dichoso" 49 .

Esta conclusión resulta inimaginable en el estilo de Laura Méndez. Su amor siempre fue más humano y menos cargado hacia el fervor. En todo caso, resultaba poco conveniente abrir el tomo de la Poesía con un texto de dudosa procedencia, y pudo haberse colocado en una sección de "Poemas atribuidos" 50 .

No se incluyeron las lecciones de algunos poemas. La lección de "Cineraria”, que fue publicada por Méndez de Cuenca en Diario del Hogar, así como una segunda edición, que apareció en el semanario Violetas, no fueron tomadas en cuenta cuando se escogió en Impresiones de una mujer a solas (pp. 71-73) ni tampoco cuando el poema se compiló en Poesía (pp. 32-34). En ambas ediciones modernas, se copió la versión que había circulado en El Siglo XIX, es decir, la más antigua ${ }^{51}$; ya desde la segunda publicación, la poetisa le había hecho cambios y correcciones importantes y, en la tercera y definitiva, se puede decir que hubo un acto de reescritura del poema.

$\mathrm{Al}$ seleccionar el poema, finalmente titulado "¡Adiós!”, en Impresiones de una mujer a solas (pp. 73-75) se había señalado la versión primera del poema, aparecida sin título en El Siglo XIX ${ }^{52}$, resuelta en versos heptasilábicos, aunque fue transcrito y publicado en alejandrinos (Mora lo explicó así a pie de página: “optamos por reproducir

49 “Un grito al corazón”, en Poesía, pp. 31-32.

50 A propósito de atribuciones a Méndez de Cuenca, Roberto Sánchez Sánchez le adjudicó el cuento "Catalepsia”, que apareció en El Lunes del Universal sin crédito del autor (México, t. 5 [lunes 21 de julio de 1890], núm. 64, pp. 1-2); lo incluyó como suyo, tanto en Simplezas y otros cuentos... (2010, pp. 109-113) como en Cuentos (M. Bazant, Laura Méndez de Cuenca. Su herencia cultural, t. 2, pp. 241-245). El autor de este cuento es el escritor español Pedro Escamilla, quien lo dio a la estampa con el título "La catalepsia. (Cuento)", en El Periódico para Todos (Madrid, tercera época, t. 1 [1880], núm. 40, pp. 629-631). En México se reprodujo en dos entregas, con el nombre del autor y el título "La catalepsia. (Narración de un paciente)", en El Correo de Occidente (Culiacán Rosales, segunda época [22 de junio de 1880], núm. 38, p. 2; e ibid. [29 de junio de 1880], núm. 39, pp. 3-4).

51 “Cineraria”, en Diario del Hogar, México, año VIII (jueves 29 de agosto de 1889), núm. 296, pp. 2-3; Violetas, Tipografía Literaria, México, t. 1 (11 de mayo de 1884), núm. 9, p. 71; y L ***, "Cineraria”, en El Siglo XIX, México, octava época, año XXIII, t. 56 (domingo 1 de marzo de 1874), núm. 10 644, p. 3.

52 L ***, “Adiós! Es necesario...”, en El Siglo XIX, México, octava época, año XXXIII, t. 56 (domingo 29 de marzo de 1874), núm. 10 672, p. 2. 
aquí los alejandrinos por cuestiones de espacio”, p. 24 n.). En Poesía, citó y transcribió la versión primera, es decir, la que había aparecido sin título y formada en heptasílabos, pero ni en el primer caso ni en esta segunda oportunidad hizo referencia a la lección del poema, resuelta en alejandrinos, que fue publicada con la nota expresa por la autora: "(Para el Diario del Hogar)", y que apareció con algunas modificaciones ${ }^{53}$. La lección de este poema fue remitido por su autora a los hermanos Luis y Agustín Cárdenas, propietarios de la Imprenta y Papelería El Lápiz de Toluca y patrocinadores del semanario que intitularon con la denominación oficial de su negocio ${ }^{54}$.

El editor transcribió del Diario del Hogar el poema "Ante Hidalgo" (Poesía, pp. 65-70), sin consignar que la primera edición había aparecido con el título "Versos patrióticos" en La Convención Radical Obre$r a^{55}$. El simple cotejo de ambas versiones hubiera puesto al editor en alerta para advertir, como lamentablemente no ocurrió, que el texto se había compuesto en décimas espinelas, porque de haberse percatado hubiera descubierto los fallos de la copia: versos faltantes y, en general, la presencia de erratas e inconsistencias que alteraron, tanto la construcción formal como el sentido del texto en la edición del Diario del Hogar, y que pasaron corregidas y aumentadas a la edición de Poesía.

Alteración del orden. La traducción que aparece con el título "De Byron”, originalmente publicada en El Lunes del Universal, fue colocada en forma indebida en el primer apartado, junto a los poemas originales (Poesía, p. 72); además, no se consignaron las más antiguas reproducciones de esta versión libre, incluidas, tanto en El Reproductor de Orizaba como en El Diario del Hogar, en ambos casos con el título "Versos que dirigió Lord Byron a su esposa, en el sexto aniversario de su matrimonio" 56 .

Casos de duplicidad textual. Hubo en la edición de Poesía algunos casos de duplicación parcial o total de poemas, lo que indica que el manuscrito no se revisó con el debido cuidado. El caso de "La Noche Triste. (Romance histórico)" resulta curioso. La poetisa lo compuso en San Francisco, California, en julio de 1896. Primero dio a la estampa

53 “¡Adiós!”, en Diario del Hogar, México, año XXI (domingo 16 de marzo de 1902), núm. 155, p. 1.

54 “¡Adiós!”, en El Lápiz. Semanario de variedades y anuncios, Av. Libertad núm. 33, Toluca, t. 1 (5 de marzo de 1905), núm. 16, p. 2.

55 "Ante Hidalgo", en Diario del Hogar, México, año IX (domingo 6 de octubre de 1889), núm. 17, p. 2; y "Versos patrióticos", en La Convención Radical Obrera, México, año II (domingo 2 de octubre de 1887), núm. 70, p. 3.

56 “De Byron. En el sexto aniversario de su matrimonio", en El Lunes del Universal, México, t. 5 (lunes 11 de agosto de 1890), núm. 85, p. 3; "Versos que dirigió Lord Byron a su esposa, en el sexto aniversario de su matrimonio", en El Reproductor. Periódico independiente, Imprenta Popular de Juan C. Aguilar, Orizaba, t. 5 (20 de noviembre de 1881), núm. 134, p. 2; y El Diario del Hogar. Periódico de las familias, Tipografía Literaria, México, t. 1 (miércoles 23 de noviembre de 1881), núm. 45, p. 1. 
un fragmento (los vv. 349-382) en Diario del Hogar, luego lo publicó en forma íntegra en el semanario capitalino La Ciudad de Dios y, casi enseguida, lo publicó en dos entregas en La Voz de México ${ }^{57}$. En Poesía, fue reproducido en forma indebida un fragmento (los vv. 349-382 citados) con el título "Al siguiente día”, como si se tratara de un poema independiente (Poesía, pp. 113-114), y más adelante se reprodujo íntegro, con lo que se incurrió en una duplicidad parcial innecesaria, además de no proporcionar información sobre las apariciones del romance en la prensa (pp. 125-136).

Cosa parecida, aunque no idéntica, ocurrió con la duplicidad íntegra del poema que Méndez de Cuenca primero tituló "Bañada en lágrimas" y dedicó “A mi hijo muerto", publicado originalmente en $\mathrm{El}$ Siglo XIX, con la lección de este mismo poema, que la autora remitió al Diario del Hogar, pero con el título definitivo de "A mi hijo muerto" 58 . En Poesía, siendo el mismo texto, pues sus variantes son mínimas, apareció dos veces: primero como "Bañada en lágrimas” (pp. 39-42) y más adelante con el título "A mi hijo muerto" (pp. 116-119).

Poemas no coleccionados. No fueron incluidos en Poesía el soneto “A Clemente Cantarell” y los poemas “A Francia”, el titulado “ ¡Nieve!", así como la versión libre del poema de Bhartrihari "Cosas del amor" 59 . Mora menciona en su "Estudio introductorio" el poema "Año nuevo", resuelto "en tercetos alejandrinos", que fue publicado en El Pueblo ${ }^{60}$, pero no explicó la causa por la cual no lo incorporó a lo coleccionado en Poesía (véase p. 24).

57 "Al siguiente día. (Fragmento del romance histórico «La Noche Triste»)", en Diario del Hogar, México, año XXII (domingo 23 de noviembre de 1902), núm. 59, p. 1; "La Noche Triste. (Romance histórico)", en La Ciudad de Dios, México, año VII (domingo 10 de septiembre de 1905), núm. 36, pp. 6-8; y "La Noche Triste. (Romance histórico)", en La Voz de México. Diario político y religioso. Órgano de los católicos de México, México (jueves 14 de septiembre de 1905), núm. 337, p. 1 (vv. 1-170); e ibid. (viernes 15 de septiembre de 1905), núm. 338, p. 1 (vv. 171-382).

58 L. Méndez, "Bañada en lágrimas”, en El Siglo XIX, México, octava época, año XXXIV, t. 67 (martes 9 de febrero de 1875), núm. 10 947, p. 2; y L. Méndez DE Cuenca, "A mi hijo muerto", en Diario del Hogar, México, año XXIII (domingo 3 de abril de 1904), núm. 172, p. 1.

59 L***, "A Clemente Cantarell”, en Corona fúnebre de Clemente Cantarell, escritor yucateco, Imprenta de Ignacio Cumplido, calle de los Rebeldes núm. 2, México, 1874, pp. 59-60; L. Méndez de Cuenca, "A Francia. Ante el monumento que guarda las cenizas de los soldados franceses y mexicanos muertos en Puebla, en cumplimiento de su deber", en El Correo de Jalisco. Diario político de noticias y anuncios, Guadalajara, Jalisco, t. 17, año IX (miércoles 17 de junio de 1903), núm. 135, [pp. 1-4]; “¡Nieve!”, en Diario del Hogar, México, año XXIII (domingo 20 de diciembre de 1903), núm. 82, p. 1; y L. Méndez de Cuenca, "Cosas del amor. (Traducido de Bhartrihari)”, en Diario del Hogar, México, año XIX (domingo 5 de agosto de 1900), núm. 277, p. 1.

60 L. Méndez de Cuenca, "Año nuevo", en El Pueblo, año IV (30 de diciembre de 1917), "Páginas literarias", [p. 1]. 
Errores de transcripción. En vida de la escritora, el poema "Infortunio" sólo fue publicado en El Siglo XIX ${ }^{61}$. Mora lo tomó del "Apéndice II" de Simplezas y otros cuentos... (pp. 423-426). En ambas fuentes modernas, se reprodujo con el faltante de los vv. 30-33, que no se copiaron de la fuente de época (Poesía, pp. 43-46).

Fuentes de acopio. La edición más antigua que Mora ha proporcionado del poema “¡Oh, corazón!” (Poesía, pp. 55-57) proviene de La República Literaria (edición del 9 de septiembre de 1883, pp. 298-299), que no se ha localizado ${ }^{62}$. Sea o no ésta, o la de La Prensa, la fuente más antigua que se ha tenido a la vista ${ }^{63}$, se consigna aquí que este poema de Méndez de Cuenca es uno de los que más veces se ha impreso, y el primero entre los que se le conocen de los que escribió y dio a conocer de su segunda etapa creativa, la cual debe datarse hacia los primeros meses de 1884, que fue cuando el matrimonio Cuenca Méndez regresaba a la Ciudad de México luego de haber vivido un tiempo corto en el puerto de Veracruz y tras de haber radicado en Orizaba, desde junio de 1880 hasta el mes de noviembre de 1883, lapso en el que Agustín F. Cuenca fue redactor responsable del periódico $\mathrm{El} \mathrm{Amigo} \mathrm{del}$ Pueblo, órgano de información y propósito electoral de la campaña de Apolinar Castillo para aspirar a la gubernatura del Estado de Veracruz. Cuenca había incursionado una temporada en la política local: fue suplente de diputado federal y regidor del Ayuntamiento de Orizaba; sin embargo, al ser derrocado el gobernador Castillo y al sentirse enfermo Cuenca, éste decidió regresar con su familia a la capital de la República, en donde casi de manera inmediata fundó el periódico El Imparcial y se empleó como redactor en La Prensa, en el puesto que dejaba vacante Juan de Dios Peza ${ }^{64}$.

Muy pronto Cuenca se agravó de sus males hepáticos, hasta que su padecimiento se volvió incurable y el pronóstico fue fatal. Su esposa se había consagrado al hogar y a la crianza de los hijos en forzoso aislamiento, y en silencio voluntario o involuntario, pero tan real como si se tratara, por un lado, de un acto de expiación o de una purga para conseguir el olvido por parte de la comunidad intelectual que la culpó desde un principio por el trágico fin que se provocó Manuel Acuña; y, por otro, debido a las necesidades y al dominio de la parte masculina dentro de su matrimonio. Lo cierto es que Méndez de Cuenca tuvo

61 L..., "Infortunio", en El Siglo XIX, México, octava época, año XXXIV, t. 67 (miércoles 17 de marzo de 1875), núm. 10 978, p. 2.

62 Entre marzo de 1886 y marzo de 1890 se publicaron en Guadalajara, Jalisco, cinco tomos de La República Literaria, impresos en la Tipográfica de Luis Pérez Verdía; ninguno data de 1883 y en los citados no apareció reproducido “¡Oh, corazón!”.

63 “¡Oh, corazón!”, en La Prensa, México, segunda época (domingo 27 de abril de 1884), núm. 45 , p. 3.

64 “[Noticia]”, en El Tiempo, México, año I (viernes 11 de enero de 1884), núm. 134, p. 2. 
que volver, con carácter de urgente, a la escena pública y empezar a escribir y a colaborar en los periódicos para conseguir medios con que atender al enfermo y sostener hogar e hijos. La poetisa abrió esta etapa creativa escribiendo, para sorpresa de todos, el cuento "La tumba del fraile", que publicó por entregas en el semanario Violetas ${ }^{65}$. En ese mismo impreso daría a la estampa, como ya se ha señalado, la segunda edición del poema "Cineraria".

Producto de esa condena de soledad y retraimiento, de ostracismo y postergación, Méndez de Cuenca maduró un nuevo registro en su forma de poetizar. Fue precisamente el momento en el que comenzó a escribir sus cuentos y a refirmar su vocación poética el que le permitió concebir y componer un grupo de poemas de calidad estética insuperable. El primer poema de esta etapa fue “¡Oh, corazón!”, el cual, por una situación anómala, luego iba a aparecer con una fecha de composición distinta. A lo mejor ésta habría sido la de la corrección para consolidar la lección del poema (o a consecuencia de un yerro de imprenta); con la nueva fecha al pie apareció en la Revista Azul: "San Francisco de California, 1894", a pesar de que desde diez años atrás ya lo había publicado en La Prensa, como se acaba de indicar ${ }^{66}$. Mora dio como fuente de “¡Oh, corazón!”, en Impresiones de una mujer a solas, la versión del periódico El Mundo (pp. 82-84) y en Poesía la versión aparecida en Diario del Hogar, en la que por cierto se reprodujo junto con su traducción al italiano, realizada por la poetisa Emma Brucchietti, dato que tampoco fue consignado por Mora ${ }^{67}$.

Se presentan como lección versiones no definitivas. Mora tomó como lección del poema "Ultratumba" la versión que se publicó en El Lunes del Universal, sin advertir que contenía algunas inconsistencias (Poesía, pp. 71-72). La primera edición del poema, que no ha proporcionado el editor moderno, permite, por el simple cotejo, comprobar estas anomalías: fue impreso por El Correo de las Señoras ${ }^{68}$.

Al igual que "¡Oh, corazón!”, el poema "Invierno" ha sido otro de los más reproducidos e inclusive recogido en revistas de Sudamérica y España, además de haber sido seleccionado en antologías. Sin embar-

65 "La tumba del fraile", en Violetas, Tipografía Literaria, México, [primera entrega]: t. 1 (23 de marzo de 1884), núm. 2, pp. 10-12; [segunda entrega]: t. 1 (30 de marzo de 1884), núm. 3, pp. 19-20; [y tercera y última entrega]: t. 1 (13 de abril de 1884), núm. 5, pp. 36-37.

66 “¡Oh, corazón!”, en Revista Azul, México, t. 2 (13 de enero de 1895), núm. 11, p. 176 .

67 “iOh, corazón!”, en El Mundo. Diario de noticias universales, eco de la opinión y resumen de la prensa, México, t. 3 (domingo 16 de marzo de 1890), núm. 212, p. 1; y Diario del Hogar, México, año V (jueves 2 de septiembre de 1886), núm. 301, p. 2.

68 "Ultratumba", en El Lunes del Universal. Diario independiente, México, t. 5 (lunes 21 de julio de 1890), núm. 64, p. 2; y "Ultratumba”, en El Correo de la Señoras. Semanario escrito expresamente para el bello sexo, México, año V (28 de noviembre de 1886), núm. 26, p. 404. 
go, al reunirlo en Poesía (pp. 74-76), sólo se presentó como fuente la versión aparecida en El Correo Español, que corresponde a la segunda edición, la cual circuló cuando la autora estaba a punto de abandonar el país para autoexiliarse en San Francisco, California ${ }^{69}$.

Cuando el editor presentó el poema "Tentación” (Poesía, pp. 77-79), sólo ofreció como fuente la primera edición, que fue incluida en El Universal ${ }^{70}$. En cambio, al presentar el titulado "Kyrie eleison" (pp. 79-81), lo enfrentó a la primera edición, aparecida en El Mercurio (18 de enero de 1893, p. 3), con la segunda, que se reprodujo en $\mathrm{El}$ Mundo. Semanario ilustrado, sin tomar en cuenta las que se reprodujeron en Diario del Hogar, El Contemporáneo, periódico de San Luis Potosí, y en El Tiempo Ilustrado y Revista Azul, de la Ciudad de México ${ }^{71}$.

Tampoco realizó el cotejo de variantes al presentar el poema "Cuarto menguante" (Poesía, pp. 82-85), pues presentó únicamente la versión aparecida en la Revista Azul, que fue la primera, y en la que, por yerro, se omitió el v. 11. Con esta inconsistencia se presentó en Poesía, no obstante la regularidad del poema, escrito en sextetas de decasílabos (esquema AABCCB). La lección del poema fue impresa en Diario del Hogar, que no fue consignada ${ }^{72}$. Pasó lo mismo con el poema "Lágrimas" (Poesía, p. 85), del que solamente se ofreció la primera versión, publicada también en la Revista Azul, sin mencionar ni consignar la lección, que apareció en Diario del Hogar ${ }^{73}$. Compiló en Poesía la segunda versión del poema "Salve" (pp. 86-87), que se había impreso en el número 21 -no en el 22- de la Revista Azul. La primera edición, con la fecha al pie "1889" fue reproducida en Diario del Hogar, y la lección del poema apareció en el semanario Revista Mexicana, que se publicaba en San Antonio, Texas ${ }^{74}$. Reprodujo asimismo en Poesía el

69 “Invierno", en El Correo Español, México, t. 2, año II (domingo 22 de febrero de 1891), núm. 918, p. 2.

70 “Tentación”, en El Universal, México, segunda época, t. 11 (domingo 31 de diciembre de 1893), núm. 33, p. 3.

71 "Kyrie eleison", en El Mundo. Semanario ilustrado, México, t. 2 (10 de octubre de 1897), núm. 15, p. 255; Diario del Hogar, México, año XXI (domingo 2 de febrero de 1902), núm. 119, p. 1; El Contemporáneo, San Luis Potosí, t. 7 (27 de marzo de 1902), núm. 1293, p. 3; El Tiempo Ilustrado, Imprenta de Victoriano Agüeros, México, año IV (domingo 15 de mayo de 1904), núm. 177, p. 11; y Revista Azul, México, segunda época, t. 6 (21 de abril de 1907), núm. 3, p. 41.

72 “Cuarto menguante", en Revista Azul, México, t. 1 (5 de agosto de 1894), núm. 15, pp. 218-219; y “Cuarto menguante”, en Diario del Hogar, México, año XV (sábado 14 de noviembre de 1896), núm. 51, p. 3.

73 “Lágrimas", en Revista Azul, México, t. 3 (26 de mayo de 1895), núm. 4, p. 52; y Diario del Hogar, México, año XXV (domingo 24 de diciembre de 1905), núm. 85, p. 1.

74 "Salve", en Revista Azul, México, t. 3 (29 de septiembre de 1895), núm. 21, p. 340; Diario del Hogar, México, año VIII (sábado 2 de febrero de 1889), núm. 120, p. 2; y Revista Mexicana. Semanario ilustrado, San Antonio, Texas, v. 2 (12 de marzo de 1916), núm. 27, p. 13. 
breve poema "En el álbum de María” (p. 87), que copió de la primera edición, impresa en la Revista Azul, pero no consignó la segunda, que apareció al año siguiente en el periódico El Mundo ${ }^{75}$.

En vida de Méndez de Cuenca se dio a la estampa tres veces el poema "Tristezas. (En el álbum de la señorita doña Amparo Loaiza)", que Mora transcribió de la primera edición, aparecida en 1896. Segundo Almanaque de Artes y Letras como única fuente (Poesía, pp. 88-89), sin enfrentarlo a las otras dos versiones. El poema fue compuesto en San Francisco, durante el mes de junio de 1895; la segunda edición circuló en El Mundo y la tercera en el semanario El Heraldo, que se editaba en Zamora, Michoacán ${ }^{76}$.

Mutilación de texto. Uno de los poemas que se transcribió en Poesía con mayor desaseo fue el titulado "Bienvenida" (pp. 148-149), que la escritora dedicó al primer jefe del Ejército Constitucionalista, Venustiano Carranza, el 14 de abril de 1916. Se publicó en El Pueblo ${ }^{77}$; al ser transcrito en Poesía se omitieron los vv. 26-27. "Bienvenida" se recitó dos veces en la Escuela Normal para Señoritas, ambas en presencia de Carranza. La primera vez durante la visita que hizo a ese plantel el 9 de junio de 1916. En El Pueblo se reseñó: "la señorita Adelaida Argüelles, de quinto año, recitó unos versos de salutación de la señora Laura Méndez de Cuenca y que hace días aparecieron en este periódico"78; y, la segunda, al celebrarse el festival de esa institución, el 1 de junio del año siguiente, cuando sería recitado por la alumna Concepción Bustamante $^{79}$.

Una de las dificultades es que el impreso de época presenta una mutilación; por eso, resulta imposible leer la primera parte del v. 26. Sin embargo, al ser transcrito en Poesía se dejaron de copiar los dos versos arriba indicados. Este poema, a pesar de su carácter circunstan-

75 "En el álbum de María”, en Revista Azul, México, t. 3 (13 de octubre de 1895), núm. 24, p. 380; y El Mundo, México, t. 1 (domingo 28 de junio de 1896), núm. 26, p. 403 .

76 “Tristezas. (En el álbum de la señorita doña Amparo Loaiza)", en 1896. Segundo Almanaque de Artes y Letras publicado por Manuel Caballero, con la colaboración de distinguidos literatos mexicanos, Imprenta y Litográfica de la Oficina Impresora de Estampillas, México, 1895, p. 51; El Mundo. Edición diaria, México, t. 1 (domingo 29 de noviembre de 1896), núm. 57, p. 5; y El Heraldo. Semanario de política e información, Zamora, Michoacán, t. 5, año V (16 de agosto de 1908), núm. 33, p. 6.

77 "Bienvenida", en El Pueblo. Diario de la mañana, México, año III, t. 1 (miércoles 19 de abril de 1916), núm. 539, p. 2.

78 "La América Latina debe formar un solo bloque continental para que pueda llenar su alta misión ante la humanidad... El C. Primer Jefe visitó ayer la Escuela Normal para Señoritas y recibió un grandioso homenaje por lo espontáneo y entusiasta” (en El Pueblo, México, año III, t. 1 [sábado 10 de junio de 1916], núm. 583, pp. 1-2).

79 "Patria, ciencia y juventud. Significativo festival en la Escuela Normal para Señoritas, en honor del señor presidente de la República” (en El Pueblo, México, año III [sábado 2 de junio de 1917], núm. 934, pp. 1 y 7). 
cial, fue resuelto en tiradas de versos pareados hexadecasílabos con monorrima consonante; esta forma, que recuerda el sistema más antiguo del romance tradicional español, por desgracia, tampoco se respetó al ser transcrito.

En este mismo caso se halla la transcripción del poema "Ya sabes el enigma" (Poesía, pp. 152-153), compuesto en pareados mixtos heptasílabos y alejandrinos, pareados o alternos, con rimas consonantes. A diferencia del anterior, la versión que apareció en la Revista de Revistas tuvo una formación impecable ${ }^{80}$; además de algunas omisiones de texto, no se copió el v. 40, con lo que se rompió la estructura formal del poema y una parte importante de su contenido.

Inconsistencias en las versiones libres. Finalmente se hará un breve repaso por la sección de "Traducciones" (Poesía, pp. 157-174). Mora compiló, con el título "A Sextio. [Ovidio]" (sic, pp. 160-161), la versión libre del latín al castellano que la poeta ensayó sobre la oda que Quinto Horacio Flaco compuso en honor de ese personaje y reunió en el Libro I de sus Odas. La atribución a Ovidio proviene de un defecto de la primera edición, que apareció en El Universal, con el título "A Sextio" y el subtítulo "Versión libre de Ovidio" impresa por Olavarría y Ferrari en la segunda época del periódico $E l$ Renacimiento -no consignada por el editor-, apareció titulada "A Sextio. (Versión libre de Horacio)". La versión definitiva, a la que tampoco se hizo mención en Poesía, fue la reproducida en Diario del Hogar, ya que presumiblemente fue remitida por la autora desde Toluca, en donde entonces residía y era subdirectora de la Escuela Normal para Señoritas ${ }^{82}$.

En circunstancias parecidas fueron incorporadas dos versiones libres que Méndez de Cuenca ensayó con sendos poemas del poeta Amaru, cuando nuestra escritora ya radicaba en Saint Louis, Missouri. Es pertinente aclarar que, como en el caso anterior, se había cometido la inconsistencia de alterar el nombre del poeta hindú, por el de "Aurora", desde la primera edición de ambas traducciones, que se publicaron juntas en La Democracia, periódico impreso en Tepic, Nayarit.

"El sueño de la abeja" fue publicado con el subtítulo "(Versión libre de Aurora $[s i c]$ )" y después se reprodujo con el mismo subtítulo en Diario del Hogar; de igual manera apareció el titulado “;Esperando!”,

80 "Ya sabes el enigma", en Revista de Revistas, México, año XI (domingo 23 de mayo de 1920), núm. 524, p. 14.

81 "A Sextio. Versión libre de Ovidio" [sic], en El Universal. Diario independiente, México, t. 5 (domingo 29 de junio de 1890), núm. 44, p. 2.

82 “A Sextio. Versión libre de Horacio", en El Renacimiento. Periódico literario, segunda época, Imprenta y Litografía de Francisco Díaz de León Sucesores, esq. de San Juan de Letrán y Rebeldes, México, 1894, pp. 118-119; y Diario del Hogar, México, año XVIII (domingo 13 de noviembre de 1898), núm. 50, p. 1. 
con el mismo subtítulo y la nota "Expresamente para La Democracia". Luego se volvió a publicar en Diario del Hogar con los mismos defectos $^{83}$. Años más tarde se copió en este mismo impreso, ahora con el subtítulo "(Poesía india de Amaru)"; al año siguiente se reprodujo en La Gaceta de Guadalajara, con el título "¿Esperando? (Poesía india de Ameru [sic] )"; reapareció con el título “¿Esperando?” en el periódico capitalino El Heraldo del Hogar, sin subtitular; en el semanario El Heraldo, papel impreso en Zamora, Michoacán, apareció con este mismo título y luego en $\mathrm{El} \mathrm{Faro}^{84}$.

Mora compiló "El sueño de la abeja" en Poesía (pp. 165-166) con el subtítulo "[versión libre de "Aurora» (sic)]", con la fuente El Diario del Hogar ( sic) [del 27 de mayo de 1900, p. 1]; y en el que tituló “EEsperando! (Poesía india de Amiru $[s i c]$ )" (p. 174) consignó a pie de página como fuente de acopio El Diario del Hogar (sic) [del 19 de marzo de 1905 , p. 1].

Fernando Tola padre ha dicho que no se sabe nada "de la vida de Amaru, con excepción de una aislada y poco fidedigna noticia de que pertenecía a la clase de los orfebres"; tampoco se sabe nada acerca del tiempo en que vivió, quizá "alrededor del año 850 después de Cristo", cuando era conocido por "una colección de estrofas (muktaka) de tema erótico"; lo más conveniente es situarlo -señaló- "entre 650 y 850 después de Cristo”. Se conserva de este poeta hindú un Shatakam, "es decir, una «Centena» de pequeños poemas de cuatro versos cada uno", aunque no todos guardan esta regularidad constructiva, ya que su obra abarca "más o menos cien estrofas". Además de dicha Cente$n a$, en algunas antologías se han conservado versos suyos, como en la titulada Subhâsitâvali o en Shârngadharapaddhati, que no fueron reunidos en Shatakam ${ }^{85}$.

Dejamos hasta aquí esta breve revisión de los editores de la poesía mendezcuenquiana. En resumidas cuentas, éstos pueden clasificarse en divulgadores y editores. A la primera categoría pertenecen Servín Ménez, García Gutiérrez y Cáceres Carenzo. En sentido riguroso, los

83 “¡Esperando! (Versión libre de Aurora [sic])”, en La Democracia, Tepic, Nayarit, año I (20 de mayo de 1900), núm. 12, p. 3; y Diario del Hogar, México, año XIX (domingo 27 de mayo de 1900), núm. 217, p. 1; y "El sueño de la abeja. (Versión libre de Aurora [sic])", en La Democracia, Tepic, Nayarit, año I (20 de mayo de 1900), núm. 12, p. 3; y Diario del Hogar, México, año XIX (domingo 27 de mayo de 1900), núm. 217, p. 1.

84 "El sueño de la abeja. [Poesía india de Amaru]", en Diario del Hogar, México, año XXIV (domingo 19 de marzo de 1905), núm. 158, p. 1; con el título “¿Esperando? (Poesía india de Ameru [sic])", en La Gaceta de Guadalajara, Guadalajara, Jalisco, año IX (domingo 22 de julio de 1906), núm. 29, p. 4; y sin el subtítulo, tanto en El Heraldo del Hogar, t. 1, México (15 de octubre de 1906), núm. 15, p. 6 como en El Heraldo. Semanario, Zamora, Michoacán, t. 4, año IV (23 de mayo de 1909), núm. 20, p. 5; y en El Faro, Tipografía El Faro, México (30 de junio de 1911), p. 415.

85 Amaru, Cien poemas de amor, versión directa del sánscrito de Fernando Tola, Eds. Corregidor, Buenos Aires, 1976, pp. 11-12. 
editores modernos han sido Gonzalo Pérez Gómez y Pablo Mora (éste con la colaboración de Sánchez Sánchez, como hemos visto y repetido). A Pérez Gómez le tocó recuperar una obra que había quedado dispersa, y lo que hizo, además de abrir el camino, sirvió de ejemplo para que un académico, con recursos materiales y técnicos, realizara la tarea de reunir la obra. Los trabajos de Mora y Sánchez Sánchez han ido en dos direcciones: dieron primero una visión "general" de todos los géneros literarios que cultivó la escritora, y después se propusieron la enorme tarea de rescatar todo lo escrito por Méndez de Cuenca. Sánchez Sánchez, en este sentido, ha llevado el mayor peso, en tanto que ha sido el compilador, además del editor y estudioso de las crónicas y de los cuentos. Creo que a partir de la reunión de las obras, empresa que se ha hecho bajo la coordinación general de Mílada Bazant, los académicos hallarán aliciente para realizar las ediciones críticas de la excepcional polígrafa del Estado de México.

Ángel José Fernández Universidad Veracruzana 